\title{
Towards the Synthesis of Mixed Actinide Particulate Reference Materials: Microscopy and Spectroscopic Characterization of U/Ce-containing Specimens
}

Todd L. Williamson ${ }^{1}$, Michael A. DeVore $\mathrm{II}^{2}$, Travis J. Tenner ${ }^{1}$, Ross Smith ${ }^{2}$, Laken Inabinent ${ }^{2}$, Jack Mershon $^{3}$, Jon Hiller ${ }^{3}$, and Matthew S. Wellons ${ }^{2 *}$

1. Savannah River National Laboratory, Aiken SC USA

2. Los Alamos National Laboratory, Los Alamos NM USA

3. Tescan USA, Warrendale PA USA

* Corresponding author: matthew.wellons@srnl.doe.gov

The detection and characterization of mixed element particulates from environmental samples collected by nuclear facilities safeguards inspectors is one of the important functions conducted by the International Atomic Energy Agency (IAEA) in support of the international Treaty on the Non-Proliferation of Nuclear Weapons. Characterization of multiple elements and their respective isotopes within single particles can reveal probative information about the material origin and age [1]. Both thermal ionization (TIMS) and secondary ion mass spectrometry (SIMS) are primary particle characterization tools for these analyses, but representative particulate (reference and proficiency testing) materials have been historically limited and/or unavailable. This material need is recognized by the IAEA as urgent; with our team and others pursuing the R\&D required to reproducibly produce single and mixed element reference particulates [25]. Initial efforts focused on $\mathrm{U} / \mathrm{Ce}$ as a convenient test surrogate for $\mathrm{U} / \mathrm{Th}$ and $\mathrm{U} / \mathrm{Pu}$ materials. $\mathrm{U} / \mathrm{Ce}$ micron-sized particles were generated and and characterized to explore synthetic strategies, exercise analytical methods, and establish any gaps for either.

Mixed U/Ce micron-sized particles were generated with a conventional aerosol generation method with a combination of uranyl and cerium oxalate feedstocks at varying $\mathrm{Ce} / \mathrm{U}$ ratios from $10^{-1}$ to $10^{-4} \mathrm{~mol} / \mathrm{mol}$ [6]. Particles were characterized by a combination of SEM/EDS, FIB, SIMS and Raman spectroscopy to assess product quality with focus on surface morphology, size, chemistry, internal structure, and inter-particle isotopic and elemental homogeneity. Initial production experiments yielded a bimodal particle distribution centered between 1-2 $\mu \mathrm{m}$ equivalent circular diameter (ECD), as characterized by automated SEM/EDS for all formulations attempted. A representative particulate is shown in Figure 1(A) and possess a spherical morphology with dimpled surface texture. Select particulates were milled by FIB to assess internal structure and demonstrated hollow cores; likely a product of untuned particle production parameters. Due to the trace quantities of Ce, SIMS methods were required to characterize elemental content and Figure (B) shows collocated particulate ion images of ${ }^{140} \mathrm{Ce},{ }^{142} \mathrm{Ce},{ }^{235} \mathrm{U}$, and ${ }^{238} \mathrm{U}$. The overlapping ion images demonstrate consistent distribution and co-location of $\mathrm{Ce}$ and $\mathrm{U}$ isotopes within the same particles.

Further SIMS measurements were conducted on $100+$ particles from $\mathrm{Ce} / \mathrm{U} 10^{-2} \mathrm{~mol} / \mathrm{mol}$ material with a focus on isotopic and elemental homogeneity as shown in Figure 2 . Both ${ }^{140} \mathrm{Ce} /{ }^{142} \mathrm{Ce}$ and ${ }^{235} \mathrm{U} /{ }^{238} \mathrm{U}$ correlation plots show high linearity as anticipated for natural and depleted $\mathrm{Ce}$ and $\mathrm{U}$ isotopic composition feedstocks, respectively. Although the LG SIMS Cameca 1280 used is a multicollector mass spectrometer; the instrument's magnet geometry required a serial analysis approach to measure $\mathrm{U}$ and $\mathrm{Ce}$ isotopic compositions for $100+$ particles. Afterwards the $\mathrm{U}$ and $\mathrm{Ce}$ ion count data was stitched together by correlation of stage coordinates. Characterization of total Ce and $\mathrm{U}$ ion counts, as shown in Figure 2(C), demonstrates a linear correlation for intraparticle $\mathrm{Ce} / \mathrm{U}$ elemental content indicative of a consistent elemental ratio. Overall the results demonstrate the potential of aerosolization-based production strategies 
for complex multi-element materials with micron dimensions. Anticipated future R\&D for U/Th and U/Pu reference particulate production and the related characterization challenges will be presented.

References:

[1] A.-L. Fauré et al Analytical Chemistry 89(12) (2018), p. 6663.

[2] T. Varjoranta et al "Development and Implementation Support Programme for Nuclear Verification 2018-2019 (STR-386)", (IAEA, Vienna Austria) January 2018.

[3] M. Wellons et al Microscopy and Microanalysis 23(Suppl 1), (2017), p. 514.

[4] R. Middendopr et al Analytical Chemistry 89(8) (2017), p. 4721.

[5] V. Trillaud et al Crystal Engineering Communications 20(48) (2018), p.7749

[6] N. Bridges et al in "2013 Savannah River National Laboratory LDRD Annual Report \#SRNL-STI2014-00096", (SRNL, Aiken SC) April 2014.
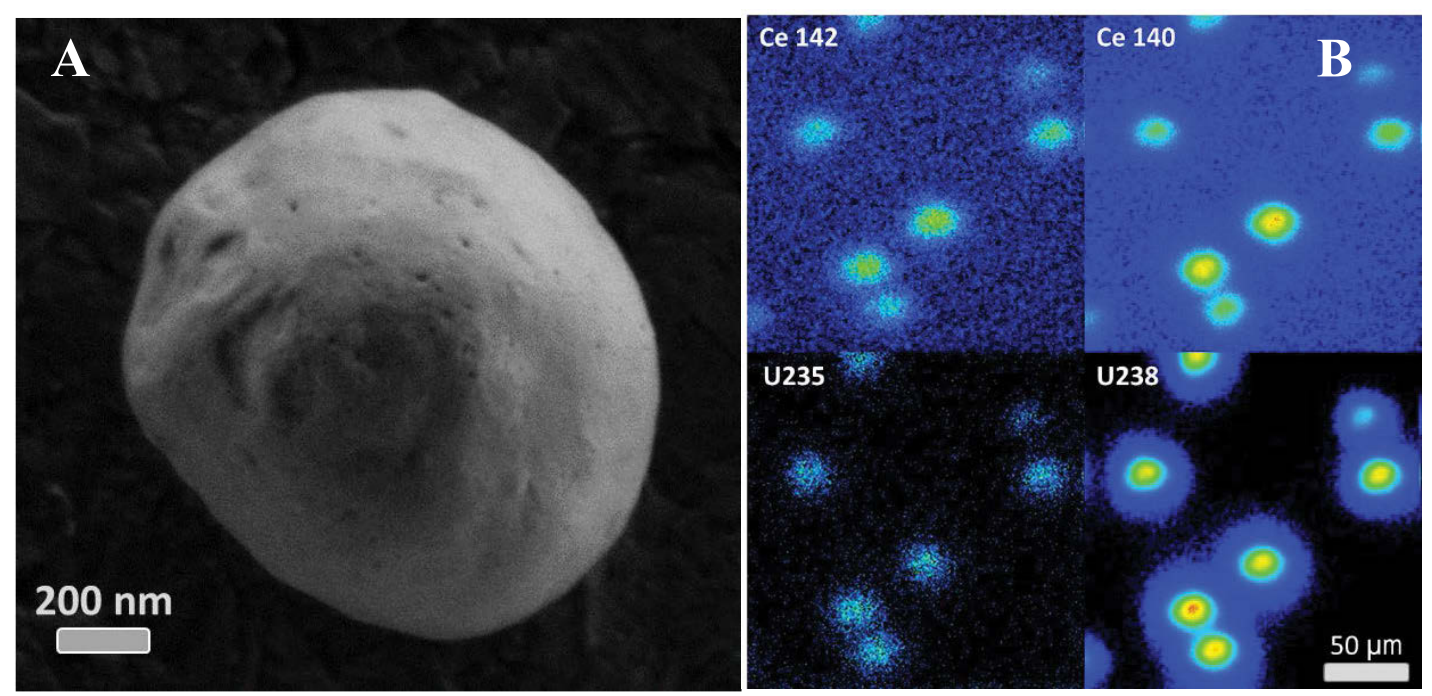

Figure 1. (A) Typical micron-sized U/Ce-containing particulate located on a vitreous carbon substrate and (B) secondary ion images of ${ }^{140} \mathrm{Ce},{ }^{142} \mathrm{Ce},{ }^{235} \mathrm{U}$, and ${ }^{238} \mathrm{U}$ within the same ROI.
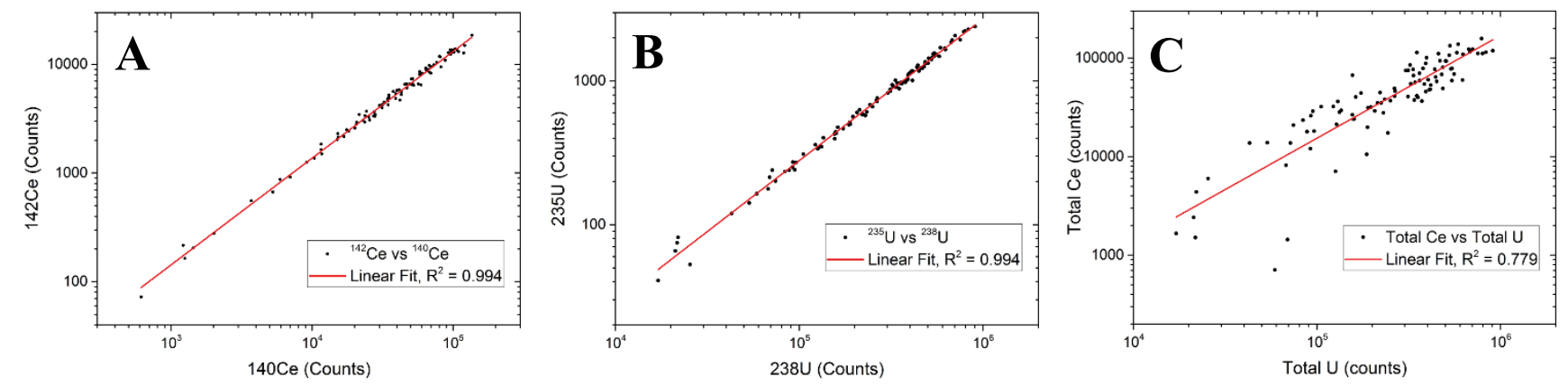

Figure 2. (A) Correlation plot of ${ }^{140} \mathrm{Ce}$ and ${ }^{142} \mathrm{Ce}$ from individual particulates; (2) Correlation plot of ${ }^{235} \mathrm{U}$ and ${ }^{238} \mathrm{U}$ from individual particulates; (3) Plot of total Ce and $\mathrm{U}$ counts per individual particulates. Ce and $\mathrm{U}$ ion counts were correlated based on each particulate stage coordinates and ion image. 